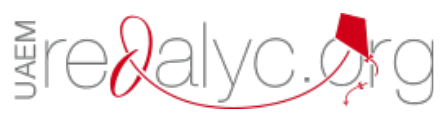

Centro Sur

ISSN: $2600-5743$

compasacademico@icloud.com

Grupo Compás

Ecuador

\title{
Estrategias para promocionar el turismo en la ciudad de Guayaquil
}

Coronel Pérez, Verónica

Estrategias para promocionar el turismo en la ciudad de Guayaquil

Centro Sur, vol. 1, núm. 1, 2017

Grupo Compás, Ecuador

Disponible en: http://www.redalyc.org/articulo.oa?id=588861699002

Esta obra está bajo una Licencia Creative Commons Atribución-NoComercial-SinDerivar 4.0 Internacional. 


\title{
Estrategias para promocionar el turismo en la ciudad de Guayaquil
}

\author{
Strategies to promote tourism in the city of Guayaquil \\ Verónica Coronel Pérez veronica.coronel@hotmail.com \\ Universidad de Guayaquil, Ecuador \\ http://orcid.org/0000-0002-0059-8618
}

Centro Sur, vol. 1, núm. 1, 2017

Grupo Compás, Ecuador

Recepción: 21 Enero 2016 Aprobación: 19 Julio 2017

Redalyc: http://www.redalyc.org/ articulo.oa?id $=588861699002$

\section{BY-NC-ND}

Resumen: La presente investigación se centra en el estudio y análisis de los ingresos del Gobierno Autónomo Descentralizado Municipal de Salinas GADMS y su impacto en la inversión pública del cantón, durante el período 2007 - 2012, fundamentada en lo que establece la Constitución de la República del Ecuador (2008), Plan Nacional del Buen Vivir, COOTAD, y Plan de Desarrollo y Ordenamiento Territorial del cantón Salinas. Los resultados indican que el GADMS, carece de disciplina fiscal, es decir incumplió la disposición legal respecto a: valoración a la propiedad urbana y rural (catastro), revisión de las tasa de funcionamiento de establecimientos turísticos (hoteles, hostales, pensiones, bares, discotecas, fuentes de soda, peñas, centros de convenciones, restaurantes, cafeterías, agencias de viajes y turismo), y otros, debilidad que incidió en la disponibilidad de recursos para atender las necesidades demandadas por la población de cada una de sus parroquias: Salinas, parroquia urbana; José Luis Tamayo y Anconcito, parroquias rurales; se demanda el servicio de alcantarillado, recolección de desechos sólidos (basura), mantenimiento de ciertas áreas de contaminación ambiental. El cantón Salinas registra pobreza por necesidades básicas insatisfecha NBI, extrema pobreza por NBI, y, la pobreza de consumo.

Palabras clave: Gobierno Autónomo Descentralizado Municipal de Salinas, presupuesto, inversiones, necesidades básicas insatisfechas, transferencias.

Abstract: This research focuses on the study and analysis of the income of the autonomous decentralized Municipal Government of Salinas GADMS and its impact on public investment of the canton, during the period 2007-2012, based on the provisions of the Constitution of the Republic of the Ecuador (2008), National Plan of the good living, COOTAD, and Development Plan and zoning of the canton Salinas. The results indicate that the GADMS, lacks fiscal discipline, i.e. breached the statutory provision regarding: evaluation to urban and rural property (catastro), review of the rate of operation of tourist establishments (hotels, hostels, inns, bars, clubs, soda fountains, penalties, conventions, restaurants, cafes, travel agencies and tourism centers), and others, weakness that affected the availability of resources to the needs demanded by the population of each of its parishes : Salinas, urban parish; José Luis Tamayo and Anconcito, rural parishes; the sewage service, solid waste (garbage), maintenance of certain areas of environmental pollution is demand. Salinas canton recorded by basic needs unsatisfied NBI, extreme poverty by NBI, poverty and consumption poverty.

Keywords: investments, decentralized self-government Municipal de Salinas, budget, transfers, unmet basic needs.

\section{INTRODUCCIÓN}

La pobreza por necesidades básicas insatisfechas (NBI) con respecto al total de la población, afecta: en el cantón Salinas al 67,1\%; en relación a la extrema pobreza por NBI, esta aqueja al $34,8 \%$ del total de la población; y la incidencia de la pobreza de consumo es del 52,7\% del total de la población del cantón Salinas. 
Analizar los ingresos y su impacto en la inversión pública del Gobierno Autónomo Descentralizado Municipal de Salinas (GADMS).

El nuevo marco legal e institucional, en el que se cobijan los gobiernos autónomos descentralizados, es el Código Orgánico de Ordenamiento Territorial, Autonomía y Descentralización, en él se transfieren competencias a los municipios y se establece una nueva forma de financiamiento para el funcionamiento de estos entes seccionales. La investigación, se justifica plenamente por la importancia de los ingresos del Gobierno Autónomo Descentralizado Municipal de Salinas, pretendiendo determinar si estos alcanzan para la realización de las inversiones y proporcionar a la población los servicios básicos fundamentales, como: alcantarillado, recolección de basura, alumbrado eléctrico, entre otros, etc, que al mismo tiempo sirven para el desarrollo de otras actividades productivas. Los GADMS realizan inversiones y proporcionan a la población los servicios básicos fundamentales, entre estos se citan: alcantarillado, recolección de basura, alumbrado eléctrico, entre otros, etc, que al a la vez son la base para el desarrollo productivo de las jurisdicciones territoriales a la que corresponden.

\section{MATERIALES Y MÉTODOS}

En la presente investigación se aplicó la siguiente metodología:

A través de la técnica de análisis documental, se revisó documentos y estudios relacionados con la realidad de las necesidades básicas de la población del cantón Salinas. Se realizó un conversatorio con las autoridades del Gobierno Autónomo Descentralizado Municipal de Salinas, directos involucrados en la problemática del cantón. Se revisó información presupuestaria y financiera del Gobierno Autónomo Descentralizado Municipal de Salinas, el método histórico, inductivo y deductivo fue útil para aprobar la hipótesis planteada, rechazarla y/o aceptarla al término de la investigación.

Según (Asamblea Nacional, 2008) Art. 238 de la Constitución de la República del Ecuador, los Gobiernos Autónomos Descentralizados gozarán de autonomía política, administrativa y financiera, y se regirán por los principios de solidaridad, subsidiariedad, equidad interterritorial, integración y participación ciudadana. En ningún caso el ejercicio de la autonomía permitirá la secesión del territorio nacional.

Constituyen gobiernos autónomos descentralizados las juntas parroquiales rurales, los concejos municipales, los concejos metropolitanos, los consejos provinciales y los consejos regionales.

La (Corporación de Estudios y Publicaciones, 2012) Mediante el COOTAD, artículo 52, referente a la naturaleza jurídica de los Gobiernos Autónomos Descentralizados Municipales, dice que son personas jurídicas de derecho público, con autonomía política, administrativa y financiera, que estarán integrados por las funciones de participación ciudadana, legislación y fiscalización, y, ejecutiva previstas en este Código, para el ejercicio de las funciones y competencias que le corresponden. 
Según (Margarita Panchana Panchana, 2014) El Gobierno Autónomo Descentralizado Municipal de Salinas "GADMS”, representa al Cantón Salinas y sus parroquias urbanas Salinas y Santa Rosa, y/o rurales José Luis Tamayo y Anconcito, y las que se crearen, y tendrá las atribuciones previstas señaladas en la constitución, código orgánico de organización territorial, autonomía y descentralización; y, demás leyes conexas.

La (Corporación de Estudios y Publicaciones, Código Orgánico de Planificación y Finanzas Públicas, Tomo III, 2012) Manual General de Contabilidad Gubernamental, dice que el Presupuesto es el instrumento de política fiscal en el cual constan las estimaciones de ingresos a obtener, así como los gastos que podrán realizarse en función del financiamiento previsto; es decir por una parte constan el origen de sus fuentes de financiamiento a través de la identificación de las diversas partidas tributarias y no tributarias y por otra el destino que se dará a los recursos financieros durante su vigencia.

Según (Margarita Panchana Panchana, 2014) Es la estimación de los recursos financieros que tiene el cantón Salinas, es decir es el instrumento que registra los ingresos (impuestos, contribuciones de mejoras, transferencias fiscales, etc) y los gastos (de servicio, producción y funcionamiento municipal para la educación, salud, seguridad, alumbrado eléctrico, etc de acuerdo a las necesidades identificadas en los sectores y al PDOT del cantón.

La (Corporación de Estudios y Publicaciones, Código Orgánico de Planificación y Finanzas Públicas, Tomo I, 2013) Con respecto a las inversiones públicas, dice que es la principal expresión de las finanzas públicas, definidas en el COPFP como el "conjunto de egresos y/o transacciones que se realizan con recursos públicos” cuya ejecución se prevé en los "planes de inversión". La priorización de los programas y proyectos de inversión corresponde a la SENPLADES, a través de la inserción en el plan anual de inversiones del presupuesto general del Estado, de acuerdo a los lineamientos fijados en el COPFP.

Según (Margarita Panchana Panchana, 2014) Son los gastos destinados al incremento patrimonial del Gobierno Autónomo Descentralizado Municipal de Salinas, mediante actividades operacionales de inversión, comprendido en programas sociales o proyectos institucionales de ejecución de obra pública. Están conformados por gastos en personal, bienes y servicios destinados a la inversión, obras públicas y transferencias de inversión.

Su devengamiento produce contablemente modificaciones directas en la composición patrimonial del Gobierno Autónomo Descentralizado Municipal de Salinas, aumentando sus inversiones en infraestructura física institucional o en bienes nacionales de uso público y en productos intangibles de desarrollo social; implica además, la concesión de transferencias sin contraprestación destinadas a la inversión.

Según la (Secretaría Nacional de Planificación y Desarrollo SENPLADES, 2013) El Buen Vivir, se planifica, no se improvisa, es la forma de vida que permite la felicidad y la permanencia de la diversidad 
cultural y ambiental, es la armonía, igualdad, equidad y solidaridad, no es buscar la opulencia ni crecimiento económico infinito.

La planificación del Buen Vivir, como su línea rectora es contraria a la improvisación que genera enormes costos a una sociedad con escases de recursos.

Los ingresos del GADMS provienen de impuestos prediales, tasas y contribuciones de mejoras, y otros, para el año 2012 generaron $\$ 15^{\prime} 672,896$, resultando totalmente insuficiente para cubrir la demanda de necesidades. El catastro municipal no ha sido actualizado desde el 2007, incumpliendo lo dispuesto en el artículo No. 139 del COOTAD, el cual señala que es obligación de los GAD actualizar cada dos años los catastros y valorar la propiedad urbana y rural. La tasa anual de funcionamiento de establecimientos turísticos (hoteles, hostales, pensiones, bares, discotecas, fuentes de soda, peñas, centros de convenciones, restaurantes, cafeterías, agencias de viajes y turismo), no ha sido actualizada desde el año 2003. La ejecución presupuestaria de gasto en personal es alta, en el año 2012 ascendió a \$7’764,902.47, representan el $50 \%$ de (Quince millones seiscientos setenta y dos mil ochocientos noventa y tres $00 / 100$ dólares), 100\% del presupuesto institucional. La vía de ingreso al cantón, y el malecón de Salinas está lleno de vallas publicitarias las cuales son generadora de ingresos, pero estas no son parte del presupuesto institución; existen aproximadamente 80 obreros en avanzada edad, con un sueldo promedio de 600 dólares c/u, quienes por insuficiencia de recursos económicos no ha sido posible liquidarlos; en similar situación existen 50 empleados con nombramiento, sueldo promedio 650 dólares. El presupuesto de ingresos por lo general es liquidado anualmente con cartera vencida, por lo que no se formulan ni aplican políticas idóneas de gestión de cobro. El servicio de alcantarillado público atiende al 37\% del total de las viviendas ubicadas en el área urbana, y 30\% del área rural. En los sectores rurales utilizan letrinas, pozos sépticos o pozos ciegos, no construidos técnicamente, ocasionando la contaminación del suelo; En la parroquia José Luis Tamayo, existe la laguna de oxidación, muy cercana a sectores residenciales, y sin ninguna clase de mantenimiento, produciendo contaminación por la emanación de olores debido a la falta de arborización y en su implantación no se consideró la dirección de los vientos. El servicio de recolección de desechos sólidos (basura) se la realiza en forma irregular y con vehículos deteriorados por el escaso mantenimiento; existen solares vacíos, llenos de maleza, donde las personas hacen sus necesidades biológicas, convertidos en basureros y guarida de malhechores. Los centros de salud carecen de profesionales para atención las 24 horas del día y sin los equipos necesarios para el desarrollo de las actividades; la ciudadanía constantemente presenta su insatisfacción por el servicio recibido. La pobreza por necesidades básicas insatisfechas (NBI) con respecto al total de la población, afecta: en el cantón Salinas al 67,1\%. En relación a la extrema pobreza por NBI, esta aqueja al 34,8\% del total de la población; y la incidencia de la pobreza de consumo es del 52,7\% del total de la población del cantón Salinas. 


\section{RESULTADOS}

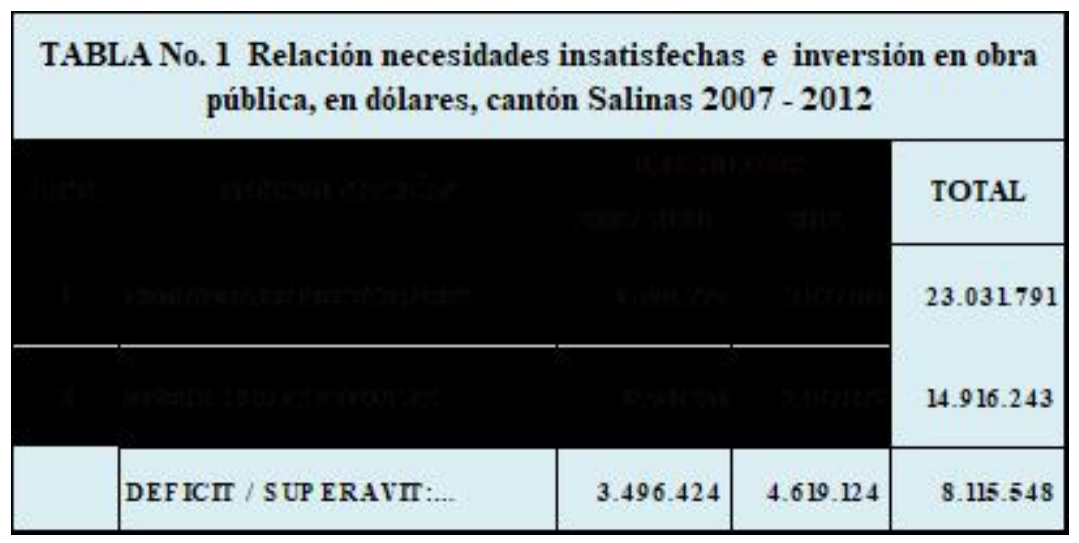

Documentos del GADMS. Elaborado por: Margarita Panchana Panchana

Hace más de una década que la población del cantón Salinas, no es atendida por sus gobernantes con inversiones en obras públicas relevantes, sus necesidades se interpretan claramente en la tabla de datos. En el año 2007 se demandaron necesidades por \$2'172.206 en obra pública, los registros presupuestarios indican que se pagó por este concepto \$1'354.350, existiendo un déficit de 817.816. En el año 2008 las necesidades tuvieron un costo de 2'043.948, se registraron pagos por 2’073.606, la diferencia se debe a ajustes de valores, es decir que el $100 \%$ de lo planificado se ejecutó.

El año 2009 también registra déficit por $\$ 956.008$, es decir que se dejaron de atender requerimientos de la ciudadanía.

Los resultados de atención a la obra pública en el 2010 son de déficit, valor que asciende a $\$ 2$ '535,741 correspondiente a la obra puerto de Anconcito, y otras, proyecto inconcluso por insuficiencia de fondos.

Para el año 2011, se determina que se realizaron desembolsos por inversión en obra pública mayores a los programados, diferencia corresponde a obras del 2010 ejecutadas en el siguiente periodo.

El período fiscal 2012 registra un déficit numérico equivalente a la suma de 4'619.124,00 (Cuatro millones seiscientos diecinueve mil ciento veinte y cuatro 00/100 dólares), como se ilustra en la tabla No. 1 .

Para el año 2012 se proyectó atender necesidades de obra pública por 7 '027.017 (Siete millones veinte y siete mil diecisiete 00/100 dólares), una vez analizado los documentos que describen la liquidación presupuestaria al 31-dic-2012, se determina que para ésta planificación solo se desembolsaron $\$ 133.420,02$ (Ciento treinta y tres mil cuatrocientos veinte 02/100 dólares), significa entonces que el nivel de ejecución alcanzó solo el $1.898 \%$, índice que está por debajo de los objetivos planteados al inicio del periodo fiscal.

La planificación no ejecutada 2012 asciende a 6'893.596.75 (Seis millones ochocientos noventa y tres mil quinientos noventa y seis, 75/100 dólares), representa el 98,102 \% del total programado para este año, equivale decir que la inversión destinada para contribuir al alcance de mejores niveles de vida en la población del cantón Salinas, conforme lo establece el Plan Nacional del Buen Vivir, es completamente baja; no así 
el nivel de insatisfacción que es del 98,102 \%, indicador que evidencia el estancamiento del desarrollo de la obra pública en este destino turístico del Ecuador y del Pacífico Sur.

En la tabla No. 44 necesidades insatisfechas, se detallan los proyectos no ejecutados al término del periodo fiscal de ejecución, año 2012.

\section{DISCUSIÓN}

La obra pública relevante con impacto en el desarrollo turístico por su gran atractivo, es el proyecto de construcción recuperación de la playa de Salinas, valorado en $\$ 3^{\prime} 614.326,55$ (Tres millones seiscientos catorce mil trescientos veinte y seis $55 / 100$ dólares); seguido de $\$ 423.222,91$ (Cuatrocientos veinte y tres mil doscientos veinte y dos 91/100 dólares) por concepto de la reconstrucción vial de varias calles de la cabecera cantonal.

Construcción del cuerpo de bomberos en la parroquia urbana Santa Rosa, Cantón Salinas, Provincia de Santa Elena, cuyo costo asciende a $\$ 381.148,39$ (Trescientos ochenta y un mil ciento cuarenta y ocho 39/100 dólares).

Los otros proyectos se vinculan con reconstrucción vial, infraestructura educativa, y construcción de cancha de uso múltiple, en las parroquias urbanas y rurales del cantón; servicios de consultorías, estudio de alcantarillado sanitario II etapa Anconcito, y otras obras de menor cuantía.

\section{CONCLUSIONES}

El presente estudio y análisis evidencia que la hipótesis planteada "Los Ingresos del Gobierno Autónomo Descentralizado Municipal de Salinas (GADMS), no permiten satisfacer las necesidades básicas de la población del Cantón”, es verdadera, realmente la situación del cantón Salinas, es apremiante.

El catastro municipal no ha sido actualizado desde el 2007 hasta la presente fecha; el Código Orgánico de Ordenamiento Territorial, Autonomía y Descentralización en su artículo No. 139 establece que es obligación de los gobiernos autónomos descentralizados municipales actualizar cada dos años los catastros y valorar la propiedad urbana y rural.

$\mathrm{La}$ tasa anual de funcionamiento de establecimientos turísticos (hoteles, hostales, pensiones, bares, discotecas, fuentes de soda, peñas, centros de convenciones, restaurantes, cafeterías, agencias de viajes y turismo), regulada con ordenanza publicada en el Registro Oficial No. 38 del 12 de marzo del 2003, no ha sido actualizada hasta la presente fecha.

La ejecución presupuestaria de gasto en personal es alta, en el año 2012 ascendió a $\$ 7^{\prime} 764,902.47$, sumatoria de $\$$ 2' 659,474.93+ $\$ 5^{\prime} 105,427.54$ ), representan el $50 \%$ de $\$ 15$ '672,896 (Quince millones seiscientos setenta y dos mil ochocientos noventa y tres 00/100 dólares), $100 \%$ del presupuesto. 
La inversión pública en el año 2012 ascendió a $\$ 2$ ‘07,893 y constituye el 15,36\% de $\$ 15^{\prime} 672,893$ (Quince millones seiscientos setenta y dos mil ochocientos noventa y tres 00/100 dólares), $100 \%$ del presupuesto para este año, observándose una distribución del ingreso inequitativa.

La pobreza por necesidades básicas insatisfechas (NBI) con respecto al total de la población, afecta: en el cantón Salinas al 67,1\%. En relación a la extrema pobreza por NBI, esta aqueja al 34,8\% del total de la población; y la incidencia de la pobreza de consumo es del $52,7 \%$ del total de la población del cantón Salinas.

La administración de ingresos y gastos, carece de disciplina fiscal. El presupuesto de ingresos por lo general es liquidado anualmente con cartera vencida, por lo que no se formulan ni aplican políticas idóneas de gestión de cobro.

\section{Referencias}

Asamblea Nacional. (2008). Constitución de la República del Ecuador. Quito, Pichincha, Ecuador.Recuperado de https://www.oas.org/juridico/mla/ sp/ecu/sp_ecu-int-text-const.pdf

Corporación de Estudios y Publicaciones. (2012). Código Orgánico de Organización, Autonomia y Descentralización. Recuperado de https://www.ministeriodegobierno.gob.ec/codigoorganico-de-organizacion-territorial-autonomia-y-descentralizacioncootad/

Corporación de Estudios y Publicaciones. (2012). Código Orgánico de Planificación y Finanzas Públicas, Tomo III. Manual General de Contabilidad Gubernamental. Recuperado de https://www.finanzas.gob.ec/wp-content/uploads/ downloads/2012/09/CODIGO_PLANIFICACION_FINAZAS.pdf

Corporación de Estudios y Publicaciones. (2013). Código Orgánico de Planificación y Finanzas Públicas, Tomo I. Estudio y Análisis de COPLAFIP. Recuperado de https://www.finanzas.gob.ec/wp-content/ uploads/downloads/2012/09/

CODIGO_PLANIFICACION_FINAZAS.pdf

Panchana Panchana,M. (2014). Los Ingresos del GADMS y el gasto en la Inversión Pública, periodo 2007-2012. Journal of business and enterreneurial studies. 2(1), 22-30

Secretaría Nacional de Planificación y Desarrollo SENPLADES. (2013). Plan Nacional del Buen Vivir, 2013-2017. Quito, Pichincha, Ecuador: SENPLADES. 